\title{
Age at First Use of Alcohol and Risk of Heavy Alcohol Use: A Population-Based Study
}

\author{
Wenbin Liang and Tanya Chikritzhs \\ National Drug Research Institute, Health Science, Curtin University, GPO Box U1987, Perth WA 6845, Australia \\ Correspondence should be addressed to Wenbin Liang; w.liang@curtin.edu.au
}

Received 7 November 2013; Accepted 12 December 2013

Academic Editor: Yuejen Zhao

Copyright ( 2013 W. Liang and T. Chikritzhs. This is an open access article distributed under the Creative Commons Attribution License, which permits unrestricted use, distribution, and reproduction in any medium, provided the original work is properly cited.

\begin{abstract}
Aim. To examine the association between age at first alcohol use and risk of heavy alcohol use among the adult US general drinking population. Methods. This population-based study used the 2010 National Survey on Drug Use and Health (NSDUH) from United States. Multivariate Poisson regression was employed to predict the frequency of heavy alcohol use (five or more drinks per occasion) in the last 30 days with age at first use of alcohol controlling for potential confounding factors. Results. Younger age at first use of alcohol was associated with increased likelihood of heavy alcohol use in the last 30 days in this population-based sample. This association remained significant when analysis was reperformed for the subgroup of participants who were with desired good health status and Kessler score lower than 12. Conclusion. Younger age at first use of alcohol was associated with increased likelihood of heavy alcohol use.
\end{abstract}

\section{Introduction}

Several studies have suggested that people who start drinking at a younger age have an increased risk of alcohol use disorders [1-6]. It has been hypothesized that the interactions among genetic and environmental factors play an important role in this observed association; however, the underlying causal mechanism is not fully understood [6]. Our recent analysis of data collected by the Australian National Drug Strategy Household Survey showed that age at first use was associated with a higher level of subsequent alcohol use among the general Australian population [7]. This association remained significant even after the analysis was limited to the population who had good (i.e., "desired") health status and low psychological distress [7]. To determine whether this observation is specific to the Australian population or generalizable, it is important to further investigate the relationship between early onset of alcohol use and heavy alcohol use in other populations. If early onset of alcohol use independently (i.e., independent of other socioeconomic and environmental risk factors) leads to heavy drinking behaviours, then it may be postulated that, to some extent, early alcohol use causes alcohol use disorders by increasing the frequency of heavy alcohol use. In this study, we aimed to examine the association between age at first alcohol use and risk of heavy alcohol use among the adult US general drinking population.

\section{Method}

Details of sampling strategy and data collection methods have been described in the 2010 National Survey on Drug Use and Health (NSDUH) report $[8,9]$. Briefly, the NSDUH is a national survey targeting the 12-year and older noninstitutionalized population of the United States. The 2010 survey used computer-assisted face-to-face interviews to collect drug use information and demographic information from respondents. In order to produce both national and state level estimates, multistage stratification and randomization combined sampling method was used [8]. In the 2010 NSDUH, participants were asked detailed questions about their alcohol use, including age at first use of alcohol. The original question was: "Think about the first time you had a drink of an alcoholic beverage. How old were you the first time you had a drink of an alcoholic beverage? Please do 
TABLE 1: Prevalence of heavy alcohol use in the last 30 days by age at first use of alcohol.

\begin{tabular}{|c|c|c|c|c|c|c|}
\hline \multirow{3}{*}{ Age at first use of alcohol } & \multicolumn{3}{|c|}{ Male } & \multicolumn{3}{|c|}{ Female } \\
\hline & \multicolumn{3}{|c|}{ Heavy alcohol use over the last 30 days } & \multicolumn{3}{|c|}{ Heavy alcohol use over the last 30 days } \\
\hline & No & Yes & $\%$ Yes & No & Yes & $\%$ Yes \\
\hline \multicolumn{7}{|c|}{ Age group $\geq 18$} \\
\hline$<12$ & 275 & 510 & $65 \%$ & 218 & 196 & $47 \%$ \\
\hline $12-14$ & 949 & 1866 & $66 \%$ & 1402 & 1315 & $48 \%$ \\
\hline $15-17$ & 2543 & 3431 & $57 \%$ & 3725 & 2363 & $39 \%$ \\
\hline $18-24$ & 2427 & 1667 & $41 \%$ & 4084 & 1179 & $22 \%$ \\
\hline$\geq 25$ & 98 & 37 & $27 \%$ & 271 & 45 & $14 \%$ \\
\hline \multicolumn{7}{|c|}{ Age group 18-29 } \\
\hline$<12$ & 126 & 314 & $71 \%$ & 121 & 137 & $53 \%$ \\
\hline $12-14$ & 459 & 1229 & $73 \%$ & 771 & 983 & $56 \%$ \\
\hline $15-17$ & 1281 & 2350 & $65 \%$ & 1941 & 1794 & $48 \%$ \\
\hline $18-24$ & 1357 & 1099 & $45 \%$ & 2066 & 788 & $28 \%$ \\
\hline$\geq 25$ & 13 & 3 & $19 \%$ & 8 & 1 & $11 \%$ \\
\hline \multicolumn{7}{|c|}{ Age group 30-49 } \\
\hline$<12$ & 103 & 159 & $61 \%$ & 72 & 53 & $42 \%$ \\
\hline $12-14$ & 360 & 527 & $59 \%$ & 518 & 303 & $37 \%$ \\
\hline $15-17$ & 856 & 859 & $50 \%$ & 1341 & 479 & $26 \%$ \\
\hline $18-24$ & 641 & 439 & $41 \%$ & 1232 & 300 & $20 \%$ \\
\hline$\geq 25$ & 60 & 24 & $29 \%$ & 155 & 27 & $15 \%$ \\
\hline
\end{tabular}

not include any time when you only had a sip or two from a drink." In the 2010 NSDUH, a "drink" was defined as "a can or bottle of beer, a glass of wine or a wine cooler, a shot of liquor, or a mixed drink with liquor in it." Participants were also asked about the frequency of heavy alcohol use over the last month. Heavy alcohol use was defined as consuming 5 or more drinks on the same occasion. The original question asked in the survey was: "During the past 30 days, that is since (the date 30 days before the interview), on how many days did you have 5 or more drinks on the same occasion? By occasion, we mean at the same time or within a couple of hours of each other" [8]. In this study, we investigated whether age at first use of alcohol predicted frequency of heavy alcohol (in the last 30 days) at older ages.

2.1. Data Analysis. Multivariate Poisson regression was employed to predict the frequency of heavy alcohol use (more than 5 drinks per occasion) in the last 30 days with age at first use of alcohol. Potential confounding factors, including current age, gender, level of achieved education, income, marital status, general health status, and psychological distress level in the last 30 days, were controlled in the model. Sampling weight provided in the dataset was applied in the analysis. The analysis was first performed with all adult participants (age $\geq 18$ ) who consumed alcohol in the last 12 months. There were 29,315 participants aged 18 years at the time of the survey and who had consumed alcohol in the last twelve months. Less than $3 \%$ of these participants did not provide necessary information on the dependent variables or some of the independent variables and therefore were excluded from the multivariate analysis. Given that heavy alcohol use was more prevalent among young adults, the analysis was independently repeated for those aged 18-29 years and 3049 years.

As noted in our previous study using an Australian sample, physical and mental morbidities may influence the relationship between age at first use of alcohol and frequency of heavy alcohol use [7]. The 2010 NSDUH included the Kessler 6 scale and a question on general health [8]. The Kessler 6 scale is a sensitive measure of the existence of nonspecific mental conditions. A score of $0-12$ indicates low risk of a mental health condition being present [10-12]. Selfreported health status with five categories (excellent, very good, good, fair, and poor) was used as the indicator of health in the survey. Self-reported health status has also been shown to be a valid and reliable measurement of general health and has been repeatedly used in the NSDUH and other national surveys [13-15]. Limiting the sample to those with a low Kessler score and good self-rated health status substantially reduces the likelihood that any observed association will be influenced by the presence of physical or mental disorders [7, $14,16-18]$. We therefore repeated the analysis on a subsample limited to those with Kessler scores of 12 or less and with a self-rating of health that was good, very good, or excellent.

In order to further control for residual confounding effects, a proxy outcome (number of days smoked in the last 30 days) was used to estimate the effects of residual confounding effects. A similar approach has been used to examine the "protective" effect of moderate alcohol use [16, 17]. This was achieved by using number of days smoked in the last 30 days as the outcome variable instead of frequency 
TABLE 2: Estimates from Poisson regression model.

\begin{tabular}{|c|c|c|}
\hline & IRR & (95\% conf. interval) \\
\hline \multicolumn{3}{|l|}{ Gender } \\
\hline Male & 1.00 & \\
\hline Female & 0.42 & $0.38-0.46$ \\
\hline \multicolumn{3}{|l|}{ Age at first use of alcohol } \\
\hline$<12$ & 3.02 & $2.50-3.65$ \\
\hline $12-14$ & 2.61 & $2.30-2.97$ \\
\hline $15-17$ & 1.93 & $1.71-2.17$ \\
\hline $18-24$ & 1.00 & \\
\hline$\geq 25$ & 1.44 & $0.77-2.69$ \\
\hline \multicolumn{3}{|l|}{ Current age } \\
\hline $18-19$ & 1.00 & \\
\hline $20-25$ & 1.57 & $1.42-1.73$ \\
\hline $26-29$ & 1.35 & $1.17-1.55$ \\
\hline $30-34$ & 1.39 & $1.19-1.64$ \\
\hline $35-49$ & 1.23 & $1.06-1.41$ \\
\hline $50-64$ & 1.02 & $0.84-1.24$ \\
\hline $65+$ & 0.60 & $0.42-0.86$ \\
\hline \multicolumn{3}{|l|}{ Highest education level attained } \\
\hline Less than high school & 1.00 & \\
\hline High school graduate & 1.04 & $0.90-1.19$ \\
\hline Some college & 0.91 & $0.78-1.05$ \\
\hline College graduate or above & 0.80 & $0.68-0.93$ \\
\hline \multicolumn{3}{|l|}{ Total family income } \\
\hline$<\$ 20,000$ & 1.00 & \\
\hline$\$ 20,000-\$ 49,999$ & 0.85 & $0.76-0.95$ \\
\hline$\$ 50,000-\$ 74,999$ & 0.89 & $0.77-1.03$ \\
\hline$\$ 75,000$ or More & 0.82 & $0.72-0.93$ \\
\hline \multicolumn{3}{|l|}{ Self-rated health status } \\
\hline Excellent & 1.00 & \\
\hline Very good & 1.03 & $0.93-1.14$ \\
\hline Good & 1.13 & $1.00-1.27$ \\
\hline Fair & 1.40 & $1.15-1.70$ \\
\hline Poor & 1.32 & $0.90-1.92$ \\
\hline \multicolumn{3}{|l|}{ Kessler score } \\
\hline$\leq 12$ & 1.00 & \\
\hline$\geq 13$ & 1.27 & $1.08-1.48$ \\
\hline \multicolumn{3}{|l|}{ Marital status } \\
\hline Married & 1.00 & \\
\hline Widowed & 1.01 & $0.68-1.49$ \\
\hline Divorced or separated & 1.47 & $1.25-1.73$ \\
\hline Never been married & 1.50 & $1.34-1.68$ \\
\hline \multicolumn{3}{|l|}{ Language used in the survey } \\
\hline English & 1.00 & \\
\hline Spanish & 0.64 & $0.50-0.81$ \\
\hline
\end{tabular}

IRR: incidence rate ratios.

of heavy alcohol use in the last 30 days, while keeping all the controlled variables unchanged. Participants included those aged 18 years at the time of the survey who had consumed alcohol in the last twelve months. This approach operates on the basis that alcohol use and tobacco use share a similar set of confounders [19-23]. We also assume that any causal relationship between age at first use of alcohol and tobacco at older ages is weaker than age at first use of alcohol and future heavy alcohol use. Any observed effects of age at first use on tobacco use were thus controlled for in the final model.

\section{Results}

From the univariate analysis, it was observed that the prevalence of consuming more than 5 drinks on the same occasion at least once in the last 30 days was significantly higher among participants who started consuming alcohol before the age of 18 years among both males and females. Similar results were observed when analyses were limited to those between 20 and 29 years and those between 30 and 49 years (Table 1). The multivariate analysis also indicated that starting to drink alcohol at a younger age was associated with significantly increased risk of heavy alcohol use over the last 30 days. Participants with less desirable health status or with a Kessler 6 score higher than 12 were significantly more likely to engage in heavy alcohol use in the last 30 days. Participants who were 65 years or older were least likely to engage in heavy alcohol use (Table 2). Among the subgroup of participants aged 20-29 years who rated their health as good, very good, or excellent and who had a Kessler score lower than 12, having consumed alcohol before the age of 18 years remained a significant risk factor for heavy alcohol use. Conversely, having first consumed alcohol at or after the age of 25 years reduced the risk of heavy alcohol use. Similar results were observed for those aged 30-49 years (Table 3).

Significant associations between age at first use of alcohol and smoking were observed. The adjusted relative risks for smoking were 1.49 (95\% confidence interval: 1.29, 1.70), 1.57 $(1.43,1.72), 1.36(1.25,1.49)$, and 1.00 (reference level) for first use of alcohol before 12 years, 12-14 years, 15-17 years, and 18-24 years, respectively. After controlling for these effects, the relative risk of heavy alcohol use by first use of alcohol remained significant, although the effect size was somewhat reduced to $2.03(1.68,2.45), 1.66(1.46,1.89), 1.41(1.25,1.59)$, and 1.00 (reference) for first use of alcohol before 12 years, $12-$ 14 years, $15-17$ years, and 18-24 years, respectively.

\section{Discussion}

In this study, we investigated the association between age at first use of alcohol and current alcohol consumption using US data from the 2010 National Survey on Drug Use and Health. Younger age at first use of alcohol was associated with increased likelihood of heavy alcohol use in the last 30 days in this population-based sample. This association was not dependent on level of psychological distress and health status. The findings of this study are consistent with the findings from a previous study of Australia's population [7]. This also suggests that the association between early onset of alcohol use and heavy alcohol consumption in later life cannot be fully explained by concurrent negative socioeconomic and environmental factors that usually influence the risk of 
TABLE 3: Association between age at first use of alcohol and likelihood of heavy alcohol use in the last 30 days among subsample with low Kessler score and good, very good, or excellent self-rated physical health.

\begin{tabular}{|c|c|c|c|c|}
\hline Age at first use of alcohol & IRR & ( $95 \%$ conf. interval) & $\mathrm{IRR}^{*}$ & (95\% conf. interval) \\
\hline \multicolumn{5}{|c|}{ Age group 18-29 } \\
\hline$<12$ & 3.30 & $2.74-3.98$ & 3.19 & $2.62-3.88$ \\
\hline $12-14$ & 3.36 & $2.98-3.78$ & 3.35 & $2.95-3.80$ \\
\hline $15-17$ & 2.44 & $2.19-2.72$ & 2.47 & $2.20-2.76$ \\
\hline $18-24$ & 1.00 & & 1.00 & \\
\hline$\geq 25$ & 0.18 & $0.06-0.51$ & 0.19 & $0.06-0.55$ \\
\hline \multicolumn{5}{|c|}{ Age group 30-49 } \\
\hline$<12$ & 2.66 & $2.04-3.45$ & 2.54 & $1.89-3.42$ \\
\hline $12-14$ & 2.06 & $1.68-2.53$ & 2.03 & $1.63-2.52$ \\
\hline $15-17$ & 1.60 & $1.32-1.94$ & 1.60 & $1.30-1.96$ \\
\hline $18-24$ & 1.00 & & 1.00 & \\
\hline$\geq 25$ & 0.40 & $0.26-0.61$ & 0.43 & $0.27-0.68$ \\
\hline
\end{tabular}

IRR: incidence rate ratios.

Models controlled for all variables showed in Table 2.

* Estimations from subsample with Kessler scores of 12 or less and a self-rating of health as good, very good, or excellent.

physical diseases and mental disorders including alcohol use disorders [14, 18, 24, 25].

The causal mechanism underlying this observed association is not fully understood. It is plausible that starting to use alcohol before the age of 18 years directly increases the risk of developing heavy alcohol use behaviours. The risk of developing habitual heavy alcohol use before the age of 18 years is nil for a person who starts drinking after the age of 18 years. However, in keeping with the relatively high prevalence of frequent heavy alcohol use among adolescents, the risk well exceeds zero for a person who starts drinking before the age of 18 years [26, 27]. In addition, compared to adults, adolescents are more likely to engage in sensationseeking and risk-taking behaviours $[9,16]$; therefore given access to alcohol, the risk of frequent heavy alcohol use may be higher in adolescence than in adulthood. It is nevertheless important that parental attitudes and behaviours during their children's initial exposure to alcohol may have substantial effects on their future consumption patterns [28-32].

The causal relationship between heavy alcohol use and alcohol use disorders is clear as heavy alcohol use is a necessary condition for the development of any alcohol use disorder; it follows therefore that increased risk of heavy alcohol use will further increase the risk of alcohol use disorders. Onset of alcohol use before the age of 18 years would therefore increase the risk of alcohol use disorders. Abstinence from alcohol until the age of 18 years will reduce the risk of alcohol-related harm. These findings are closely relevant to legislations on minimum drinking age.

\section{Conclusion}

Younger age at first use of alcohol was associated with increased likelihood of heavy alcohol use.

\section{Acknowledgments}

This work was supported by the Australian Government Department of Health and Ageing under the National Drug Strategy's funding of the National Drug Research Institute and the US National Institutes of Health (Grant no. 1R01AA019939-01A1).

\section{References}

[1] D. A. Dawson, R. B. Goldstein, S. Patricia Chou, W. June Ruan, and B. F. Grant, "Age at first drink and the first incidence of adult-onset DSM-IV alcohol use disorders," Alcoholism, vol. 32, no. 12, pp. 2149-2160, 2008.

[2] L. von Diemen, D. G. Bassani, S. C. Fuchs, C. M. Szobot, and F. Pechansky, "Impulsivity, age of first alcohol use and substance use disorders among male adolescents: a population based casecontrol study," Addiction, vol. 103, no. 7, pp. 1198-1205, 2008.

[3] D. J. DeWit, E. M. Adlaf, D. R. Offord, and A. C. Ogborne, "Age at first alcohol use: a risk factor for the development of alcohol disorders," American Journal of Psychiatry, vol. 157, no. 5, pp. 745-750, 2000.

[4] Y. A. Bonomo, G. Bowes, C. Coffey, J. B. Carlin, and G. C. Patton, "Teenage drinking and the onset of alcohol dependence: a cohort study over seven years," Addiction, vol. 99, no. 12, pp. 1520-1528, 2004.

[5] A. Agrawal, C. E. Sartor, M. T. Lynskey et al., "Evidence for an interaction between age at first drink and genetic influences on DSM-IV alcohol dependence symptoms," Alcoholism, vol. 33, no. 12, pp. 2047-2056, 2009.

[6] R. W. Hingson, T. Heeren, and M. R. Winter, "Age of first onset of alcohol dependence and subsequent episodes and severity of dependence," Alcoholism-Clinical and Experimental Research, vol. 30, no. 6, pp. 166a-166a, 2006.

[7] W. Liang and T. Chikritzhs, "The association between age at first use of alcohol and alcohol consumption levels among adult general drinking population," Journal of Public Health, vol. 20, no. 6, pp. 615-620, 2012. 
[8] SAMHSA, Results From the 2010 National Survey on Drug Use and Health: Summary of National Findings, Substance Abuse and Mental Health Services Administration, 2011.

[9] U.S. Department of Health and Human Services, Substance Abuse and Mental Health Services Administration, and Center for Behavioral Health Statistics and Quality, "National Survey on Drug Use and Health," Inter-university Consortium for Political and Social Research (ICPSR), 2010.

[10] R. C. Kessler, J. G. Green, M. J. Gruber et al., "Screening for serious mental illness in the general population with the K6 screening scale: results from the WHO World Mental Health (WMH) survey initiative," International Journal of Methods in Psychiatric Research, vol. 19, no. 1, pp. 4-22, 2010.

[11] T. A. Furukawa, R. C. Kessler, T. Slade, and G. Andrews, "The performance of the K6 and K10 screening scales for psychological distress in the Australian National Survey of Mental Health and Well-Being," Psychological Medicine, vol. 33, no. 2, pp. 357-362, 2003.

[12] R. C. Kessler, T. C. Wai, O. Demler, and E. E. Walters, "Prevalence, severity, and comorbidity of 12-month DSM-IV disorders in the National Comorbidity Survey Replication," Archives of General Psychiatry, vol. 62, no. 6, pp. 617-627, 2005.

[13] D. L. McGee, Y. Liao, G. Cao, and R. S. Cooper, "Selfreported health status and mortality in a multiethnic us cohort," American Journal of Epidemiology, vol. 149, no. 1, pp. 41-46, 1999.

[14] W. Liang and T. Chikritzhs, "Reduction in alcohol consumption and health status," Addiction, vol. 106, no. 1, pp. 75-81, 2011.

[15] E. L. Idler and Y. Benyamini, "Self-rated health and mortality: a review of twenty-seven community studies," Journal of Health and Social Behavior, vol. 38, no. 1, pp. 21-37, 1997.

[16] W. Liang and T. Chikritzhs, "Alcohol consumption and health status of family members: health impacts without ingestion," Internal Medicine Journal, vol. 43, no. 9, pp. 1012-1016, 2013.

[17] W. Liang and T. Chikritzhs, "Observational research on alcohol use and chronic disease outcome: new approaches to counter biases," Scientific World Journal, vol. 2013, Article ID 860915, 14 pages, 2013.

[18] W. Liang and T. Chikritzhs, "Affective disorders, anxiety disorders and the risk of alcohol dependence and misuse," British Journal of Psychiatry, vol. 199, no. 3, pp. 219-224, 2011.

[19] W. R. True, H. Xian, J. F. Scherrer et al., "Common genetic vulnerability for nicotine and alcohol dependence in men," Archives of General Psychiatry, vol. 56, no. 7, pp. 655-661, 1999.

[20] R. A. Grucza and L. J. Bierut, "Co-occurring risk factors for alcohol dependence and habitual smoking: update on findings from the Collaborative Study on the Genetics of Alcoholism," Alcohol Research and Health, vol. 29, no. 3, pp. 172-178, 2006.

[21] M. T. Lynskey and D. M. Fergusson, "Childhood conduct problems, attention deficit behaviors, and adolescent alcohol, tobacco, and illicit drug use," Journal of Abnormal Child Psychology, vol. 23, no. 3, pp. 281-302, 1995.

[22] P. N. Ritchey, G. S. Reid, and L. A. Hasse, "The relative influence of smoking on drinking and drinking on smoking among high school students in a rural tobacco-growing county," Journal of Adolescent Health, vol. 29, no. 6, pp. 386-394, 2001.

[23] M. Zuckerman and D. M. Kuhlman, "Personality and risktaking: common biosocial factors," Journal of Personality, vol. 68, no. 6, pp. 999-1029, 2000.

[24] W. Liang and T. N. Chikritzhs, "Brief report: marital status and alcohol consumption behaviours," Journal of Substance Use, vol. 17, no. 1, pp. 84-90, 2012.
[25] W. Liang, T. Chikritzhs, and K. M. Fillmore, "Mental disorders the missing piece?" Addiction, vol. 105, no. 8, pp. 1497-1498, 2010.

[26] J. Swendsen, M. Burstein, B. Case et al., "Use and abuse of alcohol and illicit drugs in US adolescents: results of the National Comorbidity Survey-Adolescent Supplement," Archives of General Psychiatry, vol. 69, no. 4, pp. 390-398, 2012.

[27] G. J. MacArthur, M. C. Smith, R. Melotti et al., "Patterns of alcohol use and multiple risk behaviour by gender during early and late adolescence: the ALSPAC cohort," Journal of Public Health, vol. 34, supplement 1, pp. i20-i30, 2012.

[28] L. Hayes, Parenting Influences on Adolescent Alcohol Use, 2004.

[29] K. A. Komro, M. M. Maldonado-Molina, A. L. Tobler, J. R. Bonds, and K. E. Muller, "Effects of home access and availability of alcohol on young adolescents' alcohol use," Addiction, vol. 102, no. 10, pp. 1597-1608, 2007.

[30] S. M. Ryan, A. F. Jorm, and D. I. Lubman, "Parenting factors associated with reduced adolescent alcohol use: a systematic review of longitudinal studies," Australian and New Zealand Journal of Psychiatry, vol. 44, no. 9, pp. 774-783, 2010.

[31] M. Windle, "Parental, sibling, and peer influences on adolescent substance use and alcohol problems," Applied Developmental Science, vol. 4, no. 2, pp. 98-110, 2000.

[32] T. J. Dishion and R. Loeber, "Adolescent marijuana and alcohol use: the role of parents and peers revisited," American Journal of Drug and Alcohol Abuse, vol. 11, no. 1-2, pp. 11-25, 1985. 


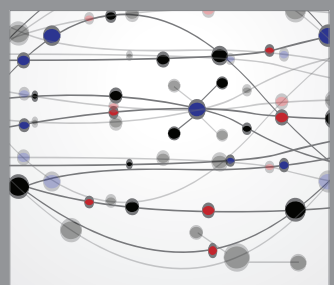

The Scientific World Journal
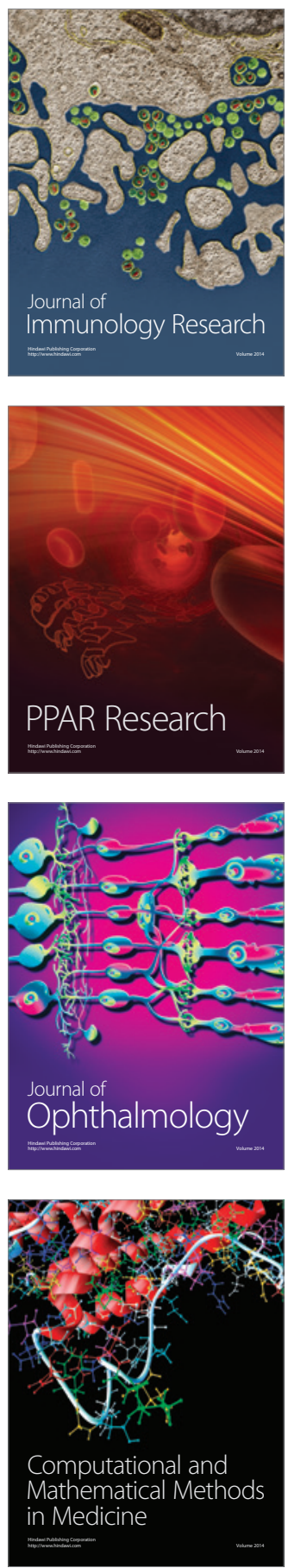

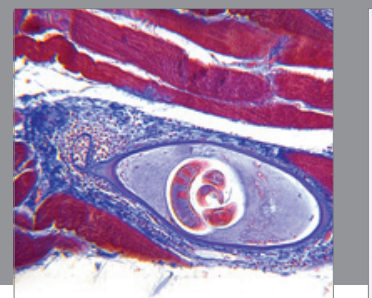

Gastroenterology

Research and Practice
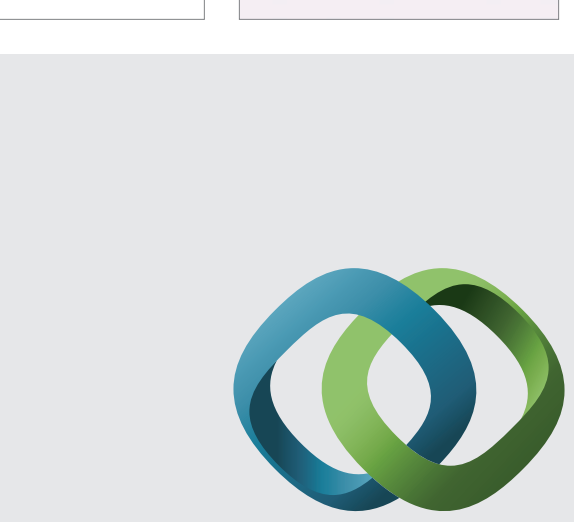

\section{Hindawi}

Submit your manuscripts at

http://www.hindawi.com
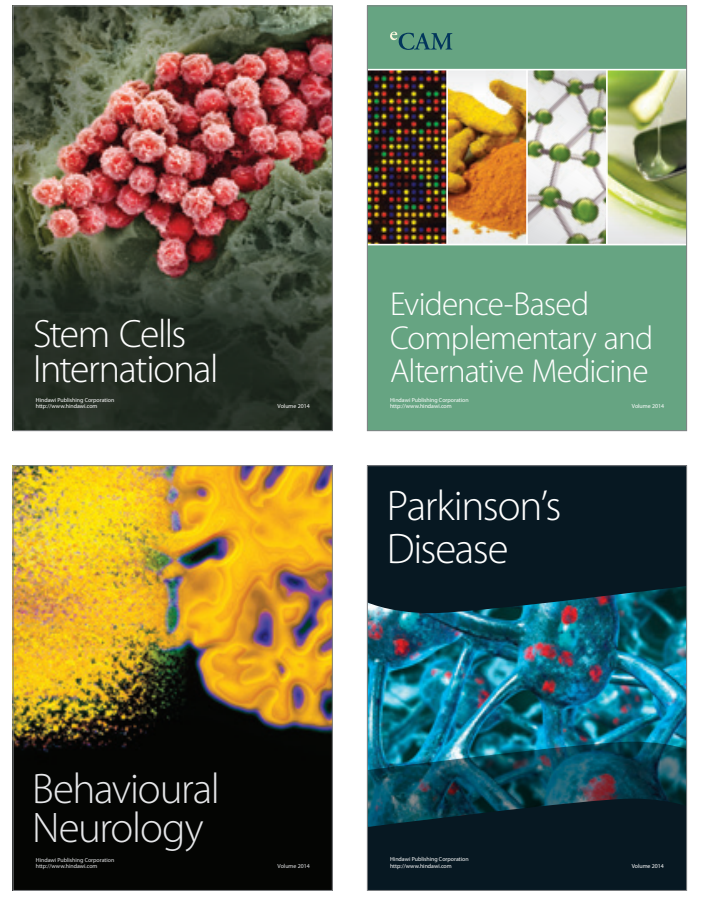
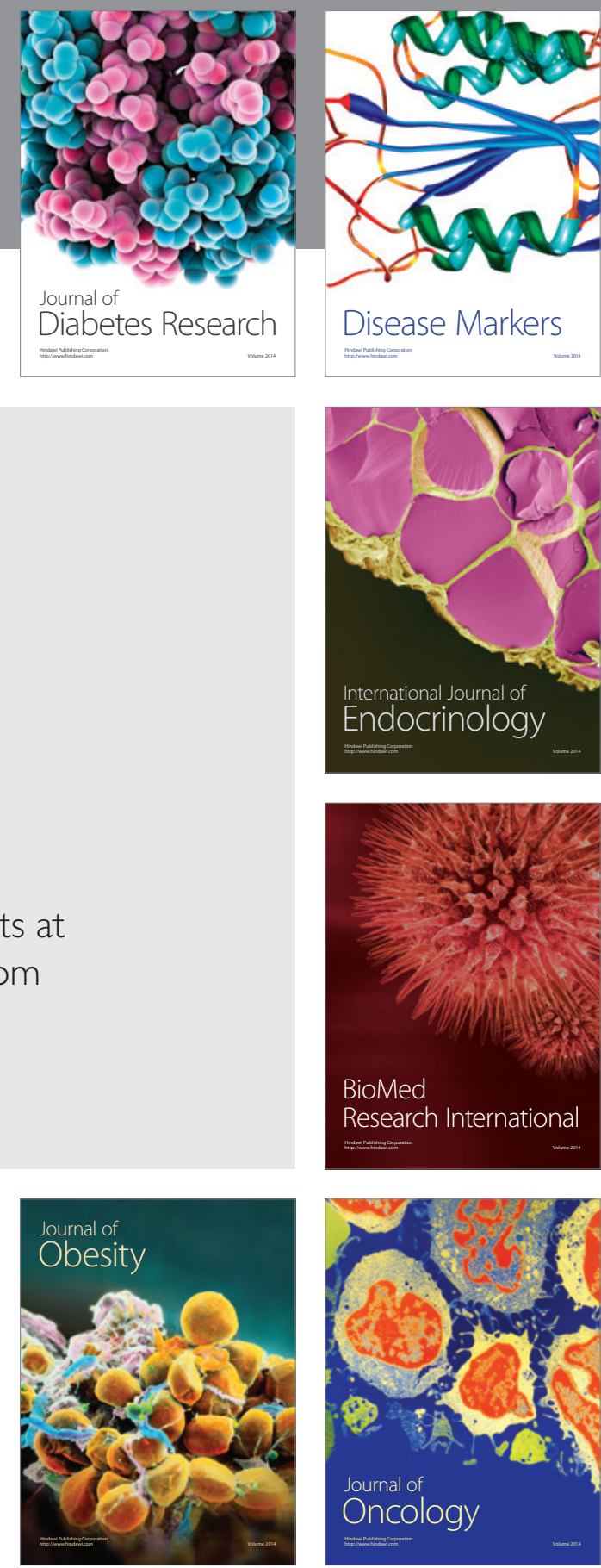

Disease Markers
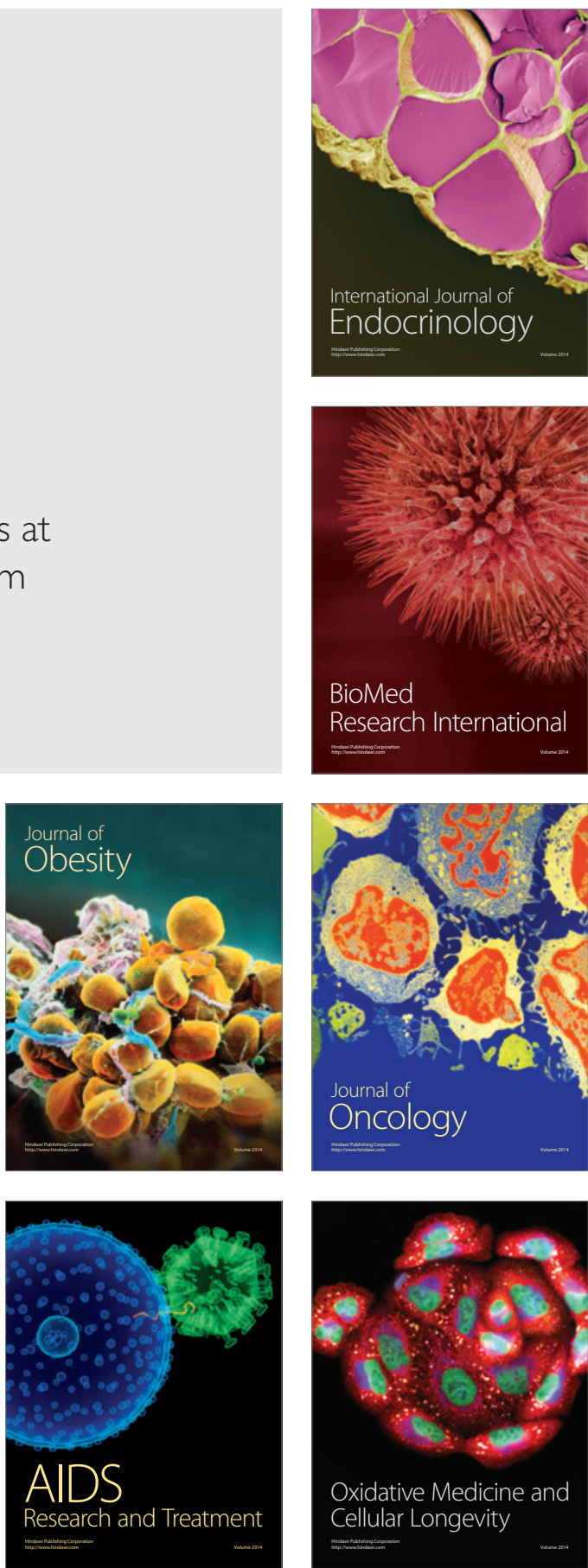